RGSA - Revista de Gestão Social e Ambiental

Set.- Dez. 2009, V.3, No.3, p.155-174

www.gestaosocioambiental.net

\title{
CONFLITOS SOCIOAMBIENTAIS ENVOLVENDO PROJETOS DE MECANISMO DE DESENVOLVIMENTO LIMPO (MDL) NA AMÉRICA LATINA
}

\begin{abstract}
Andréa Cardoso Ventura ${ }^{1}$ José Célio Silveira Andrade ${ }^{2}$

\section{RESUMO}

O Protocolo de Kyoto surge em 1997 como uma pretensa solução para o aquecimento global, Apenas um dos seus mecanismos permite a participação direta dos países em desenvolvimento: o Mecanismo de Desenvolvimento Limpo (MDL). A proposta deste mecanismo é que os países em desenvolvimento possam contribuir para a redução de gases do efeito estufa usando financiamento dos países desenvolvidos e, ao mesmo tempo, promovam o desenvolvimento sustentável. No entanto, não há um consenso os atores sociais envolvidos sobre a eficácia dos projetos MDL. Um número crescente de ONGs os critica, argumentando que não há contribuição para o meio ambiente global e para o desenvolvimento sustentável com o MDL. Este trabalho apresenta os resultados de uma investigação que analisou, através de um estudo de caso comparativo, dois diferentes projetos MDL na América Latina: o Projeto Plantar, no Brasil, e o Projeto Fray Bentos de Biomassa, no Uruguai. Os casos têm pelo menos um ponto comum: ambos envolvem conflitos socioambientais entre empresas privadas e ONGs sobre plantações de eucalipto em escala industrial. Através de revisão bibliográfica e documental, entrevistas com os principais atores envolvidos em cada caso, e da observação não participante, este artigo tenta analisar as principais semelhanças e diferenças entre estes conflitos. Observa-se que, não obstante as diferenças marcantes existentes, os casos são ligados em aspectos-chave, a exemplo da contestação ao modelo de desenvolvimento apoiado pelos projetos de MDL e da forma de contestação utilizada pelos integrantes do movimento social ambientalista de oposição.
\end{abstract}

Palavras-chave: Conflitos socioambientais; Mecanismo de Desenvolvimento Limpo (MDL); América Latina.

\section{ABSTRACT}

The Kyoto Protocol comes up in 1997 as a supposed solution to global warming. Only one of its mechanisms allows direct participation of developing countries: the Clean Development Mechanism (CDM). The purpose of this mechanism is that developing countries can contribute to reduce Greenhouse Gas Emissions using funding from developed countries and, at the same time, promote sustainable development. However, there is not a consensus on CDM projects effectiveness among the social actors involved. A growing number of NGOs criticize them, arguing that there is not any contribution to the global environment and sustainable development with the CDM. This paper presents the results of an investigation that examined, through a comparative case study, two different CDM projects in Latin America: Plantar Project in Brazil and the Project Biomass Fray Bentos in Uruguay. The

\footnotetext{
Pesquisadora do Labmundo/NPGA/UFBA e Mestre em Administração pela UFBA. E-mail: andreaventurassa@gmail.com.

${ }^{2}$ Professor do Labmundo/NPGA/UFBA, Pós-Doutor pela Université Laval, Québec, Canadá e Doutor em Administração pela UFBA. E-mail: celio.andrade@superig.com.br.
} 
cases have at least one point in common: both involve social and environmental conflicts between private companies and NGOs on eucalyptus plantations in industrial scale. Through literature and documentary review, interviews with key actors involved in each case, and nonparticipant observation, this article attempts to analyze the similarities and differences between these conflicts. It is observed that, despite marked differences, the cases are linked to key aspects, such as the challenge to the development model supported by the CDM projects and the contestation methods used by the social environmentalist movement of opposition.

Key Words: Social Environmental Conflicts; Clean Development Mechanisms (CDM); Latin America.

\section{INTRODUÇÃO}

A temática das mudanças climáticas já é uma constante nos mais diversos setores e aspectos sociais. Ambientes científicos e acadêmicos, lideranças empresariais, governantes de países desenvolvidos e em desenvolvimento, integrantes de movimentos sociais: todos discutem alternativas para minimizar os efeitos de uma catástrofe pré-anunciada. Mesmo entre os que acreditam que há exageros nas previsões de grandes inundações, escassez de alimentos, secas, migrações em massa, entre outros impactos da alta concentração de Gases do Efeito Estufa (GEE) na atmosfera terrestre, há certo consenso de que algo precisa ser feito. $\mathrm{O}$ interesse pelo assunto atinge organizações e indivíduos em todo o mundo.

Desde a tomada de consciência sobre a finitude dos recursos naturais, há quase quatro décadas, as nações vêm buscando, via diplomacia internacional, formas coletivas de amenizar os impactos da ação antrópica sobre o meio ambiente. Constatou-se a necessidade de construção de novas formas de governança ambiental global, visando ao "gerenciamento" destas questões. Nesse momento histórico, ocorrido no início da década de 1970, já se sabia da necessidade de uma ação conjunta de indústrias, sociedade e governo de todos os países, sendo impossível pensar exclusivamente nos interesses nacionais. O que está em jogo é um bem público global.

Entre as alternativas apresentadas, encontram-se temas como a redução drástica no nível de consumo mundial, a alteração da matriz energética mundial, ancorada no uso de combustíveis fósseis não renováveis, o desenvolvimento de tecnologias mais ecos-eficientes. No entanto, o instrumento que mais vem despertando a atenção de estudiosos e da própria mídia é o Protocolo de Kyoto, mecanismo multilateral para a redução dos GEE sob a atmosfera, assinado em 1997 e em vigor desde 2005. Trata-se do primeiro mecanismo global a estipular metas reais de redução na emissão destes gases.

Entre as principais razões da atenção dada ao Protocolo, estão as dúvidas levantadas, especialmente por parte de integrantes de movimentos sociais ambientalistas, sobre a efetividade ambiental das propostas e projetos embutidos neste acordo. Argumenta-se, principalmente, que se trata de um instrumento puramente mercadológico, que permitiria (e até mesmo, estimularia) a perpetuação no modelo de desenvolvimento adotado pelo acordo e nos benefícios que seriam adquiridos pelos países do Norte em relação aos do Sul (SouthSouthNorth, 2004; Ventura, 2008).

Esta questão torna-se ainda mais evidente quando se toma por objeto de análise um dos três mecanismos de flexibilização, incluídos no Protocolo objetivando a facilitar o alcance das metas de redução: o Mecanismo de Desenvolvimento Limpo (MDL). Em linhas gerais, o MDL permite que países desenvolvidos contabilizem parte de suas reduções de GEE através de projetos por eles financiados, e realizados em países em desenvolvimento, que, em um primeiro momento, não possuem metas assumidas frente ao acordo.

Verifica-se um número crescente de atores questionando esse mecanismo de governança ambiental global, que envolve a interação entre empresas, sociedade civil e governo de nações 
de todo o mundo. Há atores sociais, a exemplo de algumas ONGs baseadas no hemisfério Sul, que apresentam duras críticas ao MDL enquanto mecanismo de governança fundamentado no comércio de emissões, sob o argumento de que se trata de uma forma encontrada pelos países industrializados do Norte de escaparem da responsabilidade de reduzirem suas emissões de GEE, dentro de suas próprias fronteiras (SouthSouthNorth, 2004). Entre os argumentos dessas ONGs encontra-se a afirmação de que o MDL é moralmente errado, visto tentar transferir a responsabilidade da solução do problema para aqueles que não o criaram. Há ainda críticas sobre a não contribuição efetiva para a solução dos problemas climáticos; a manutenção de altos índices de emissão de GEE nos países desenvolvidos, a lógica focada exclusivamente nos interesses de mercado, entre outras.

Desta forma, considerando-se que as discussões mundiais acerca das mudanças climáticas são, de acordo com Viola (2005), dominadas por países do Norte, torna-se extremamente interessante conhecer o posicionamento do movimento antiglobalistas (considerando-se aqui sua luta anti-hegemônica, conforme categorizam Echart, López e Orozco, 2005) sobre projetos de MDL que estão sendo desenvolvidos na América Latina, auxiliando países do Norte para o atingimento de suas metas de redução de GEE. A América Latina vem tendo uma participação expressiva no desenvolvimento de projetos de MDL. De acordo com dados da United Nations Framework on Convention Climate Change (UNFCCC, 2009), em 09 de julho de 2009 havia 1717 projetos desta natureza aprovados em todo o mundo. Destes, 427 (24,9\%) estão sendo desenvolvidos na América Latina e no Caribe, segundo bloco geográfico com maior número de projetos de MDL no mundo, atrás da Ásia, com $72,8 \%$.

Por este motivo, esta pesquisa propôs-se a analisar o posicionamento de movimentos de contestação a dois projetos de MDL desenvolvidos na América Latina, sendo um no Brasil, e um no Uruguai. O Brasil detém a liderança entre os projetos latinoamericanos, hospedando 160 experiências de MDL, seguido proximamente pelo México, com 117 projetos. Na sequência, aparecem Chile (33), Peru (18), Colômbia (15), Guatemala (9), entre outras participações menores, a exemplo do Uruguai, com apenas três projetos de MDL aprovados no âmbito do Protocolo (UNFCCC, 2009).

Os dois projetos de MDL objeto de análise foram escolhidos, justamente, por terem recebido, em algum momento de seu ciclo de avaliação e implantação, críticas por parte de integrantes do movimento ambientalista. Foram eles:

1) Projeto Plantar - Projeto de Biomassa Cultivada como Fonte de Energia Renovável para a Produção de Ferro Gusa

Razões da escolha: a) um dos pioneiros a negociar créditos de carbono no Brasil; b) primeiro projeto mundial financiado pelo Protocol Carbon Fund (PCF), fundo ligado ao Banco Mundial; c) utilização da controvertida metodologia de "sumidouros de carbono"; d) ocorrência de grande mobilização social contrária ao projeto.

2) Projeto Botnia - Fray Bentos Projeto de Geração de Energia Através de Biomassa ("Fray Bentos Biomass Power Generation Project”)

Razões da escolha: a) projeto realizado no Uruguai pela subsidiária de uma empresa finlandesa, país com metas a cumprir com o Protocolo de Kyoto; b) antes mesmo da apresentação de seu de MDL, a empresa enfrentava fortes conflitos socioambientais contrários à sua implantação.

O estudo utilizou como estratégia metodológica a realização de estudo de caso comparativo, baseado em pesquisa bibliográfica (livros, revistas e artigos científicos, documentos institucionais, teses doutorais e dissertações de mestrado), pesquisa de campo envolvendo desde a análise documental de dados secundários (documentos oficiais da Botnia e da Plantar, matérias publicadas em websites ambientalistas e de movimentos sociais contestatórios, cobertura da imprensa sobre a questão), como a obtenção e análise de dados 
primários (entrevistas semi-estruturadas com integrantes do movimento contrário ao projeto de MDL da Botnia e da Plantar).

Apresenta-se, no presente artigo, um resumo sobre as principais conclusões deste estudo, que culminou na elaboração de uma tesina desenvolvida pela primeira autora, sob a orientação do segundo autor, no âmbito do Máster en Estudios Contemporâneos en América Latina, coordenado pela Universidad Complutense de Madrid.

Optou-se, assim, por estruturar o presente trabalho em quatro partes distintas, além desta introdução e das conclusões finais. Na primeira delas, apresenta-se um panorama sobre conflitos socioambientais relativos a projetos de MDL; na segunda, demonstra-se o modelo analítico adotado; na terceira, descrevem-se os projetos de MDL analisados, juntamente com as principais críticas a eles realizadas; finalizando-se por, na quarta seção, apresentar uma reflexão sobre as principais semelhanças e diferenças encontradas entre os dois projetos.

\section{PROJETOS DE MDL E CONFLITOS SOCIOAMBIENTAIS}

O Protocolo de Kyoto foi criado em 1997, ratificado por 132 países. No entanto, o instrumento somente entrou em vigor em 2005, com o atingimento de um número mínimo de países desenvolvidos participantes que correspondessem, ao menos, por 55\% do total de emissões desses gases, tomando-se como referência os níveis de 1990. Esta era uma condição básica para sua vigência: A meta é que, em um primeiro período de vigência, compreendido entre 2008 e 2012, 38 países desenvolvidos reduzam suas emissões, em média, 5,5\% abaixo dos níveis de referência, sendo possível atingir a redução de até 61,6\% (Lopes, 2002).

Um dos principais entraves enfrentados durante sua formulação relacionava-se à participação dos países em desenvolvimento no cumprimento das metas, tendo em vista que, comprovadamente, os países desenvolvidos tiveram maior responsabilidade pelos níveis atuais de GEE na atmosfera. Por este motivo, a Convenção-Quadro das Nações Unidas sobre Mudanças Climáticas (CQNUMC) divide os países em categorias para o estabelecimento de metas, ou não. O chamado "Anexo I" é formado por dois subgrupos - países do "Anexo II”, composto pelas nações ricas, grupo bastante semelhante à Organização de Comércio e Desenvolvimento Econômico (OCDE), em termos de componentes, e os países denominados "Economias em Transição", abrangendo países da Europa Oriental e a maioria dos países da antiga União Soviética -, sendo que seus integrantes possuem metas de redução; e os "NãoAnexo I", categoria formada pelos países em desenvolvimento, sem metas definidas para o primeiro período de vigência do Protocolo (Ventura \& Andrade, 2006).

O Protocolo estabelece, assim, que as reduções de emissão de GEE e/ou a remoção de CO2 dar-se-á por três mecanismos distintos. Dois destes - a "Implementação Conjunta" e o "Comércio de Emissões" -, têm sua atuação restrita aos países desenvolvidos ou industrializados. Já o terceiro, o "Mecanismo de Desenvolvimento Limpo" (MDL), permite a participação de países em desenvolvimento, como é o caso de Brasil e Uruguai. O propósito inicial da inclusão desse último mecanismo no rol de estratégias do Protocolo foi garantir assistência para que os países em desenvolvimento viabilizassem o seu desenvolvimento sustentável, contribuindo, ao mesmo tempo, para a redução global dos GEE na atmosfera. Este objetivo seria atingido através da implementação de projetos de redução e/ou seqüestro desses gases em países em desenvolvimento, financiados por países desenvolvidos. Podem participar de uma atividade de projeto de MDL países integrantes do "Anexo I”, países "NãoAnexo I” ou entidades públicas e privadas dessas nações, desde que por elas devidamente autorizadas. Essas atividades ainda podem ser implementadas por meio de parcerias entre o setor público e privado, envolvendo investimentos em tecnologias mais eco-eficientes, substituição de fontes de energias fósseis por renováveis, racionalização do uso da energia, florestamento e reflorestamento, entre outras (Lopes, 2002). 
De acordo com Viola (2005), esse é um dos pontos de maior impacto trazidos pelo Protocolo de Kyoto para as negociações internacionais. A redução da emissão de gases gera uma nova "moeda" no mercado financeiro mundial. Esse crédito pode ser entendido como um benefício, um prêmio recebido por uma empresa ou nação como recompensa por seus esforços em evitar ou reduzir suas emissões de GEE, ou então por retirar gás carbônico da atmosfera, ato que nesse mercado recebe o nome de "seqüestro" ou remoção. Essa recompensa viria na forma de títulos representativos dos Créditos de Carbono conquistados, denominados Reduções Certificadas de Emissões (RCEs).

Esses certificados representam créditos que podem ser utilizados pelos países do "Anexo I" como um modo de cumprimento parcial de seus objetivos. Com isso, parte do compromisso de redução pode ser comprovado através da aquisição de RCEs emitidas por outro país. A idéia é que, sendo a atmosfera terrestre única, abrangendo todos os países do mundo, a redução de gases efetuada em uma nação terá impacto positivo para o clima como um todo. Dessa forma, a quantidade de gases reduzida por um país pode ser comprada por outro. Essas negociações são realizadas através das RCEs.

Como ocorre em todas as questões que envolvem o meio ambiente, também em projetos de MDL há diferentes visões sobre como os recursos naturais estão sendo utilizados ou tratados. O meio ambiente um bem coletivo e cada um dos atores direta ou indiretamente envolvidos possui sua própria forma de entender como ele deve ser aproveitado, ocorrendo, assim, os conflitos socioambientais. E é nessa perspectiva, na disputa dos interesses pelo uso desse bem, que surgem os conflitos (Instituto Brasileiro de Análises Sociais e Econômicas [IBASE], 1995).

Conflitos socioambientais podem ser entendidos como disputas entre grupos sociais oriundas dos diferentes tipos de relação que estes mantêm com seu meio natural (Little, 2001, apud Torres, Costa e Silva \& Cunha, 2005). Considerando-se que cada conflito relaciona-se com seus ambientes naturais particulares, juntamente com seus atores sociais e relações próprias, esse autor propõe três procedimentos básicos, necessários à sua análise: a) identificação e análise dos principais atores envolvidos no conflito, tomando por base seus interesses econômicos e ambientais; b) identificação e análise dos principais agentes naturais envolvidos no conflito; e, c) análise sintética e global do conflito, incluindo a identificação de impactos ambientais.

As críticas do movimento ambientalista ao Protocolo de Kyoto encontram-se expostas em publicações de algumas de suas organizações integrantes. Como exemplo da argumentação contrária aos projetos de MDL utilizada por este ator social tem-se publicação da SouthSouthNorth (2004), onde se afirma que a principal questão em jogo é a eficiência econômica (visto ser mais viável, financeiramente, realizar projetos de redução de emissão nos países subdesenvolvidos). Para esses críticos, faz-se necessário que os países do Sul, a exemplo do Brasil, desenvolvam capacidade político-institucional de avaliação dos projetos de MDL, verificando a sua efetividade socioambiental e sua efetiva contribuição para o desenvolvimento sustentável.

Milani e Keraguel (2007) afirmam existir a constante presença da discussão sobre o conceito de desenvolvimento sustentável nas críticas ambientalistas. Para eles, isso ocorre porque ainda não houve o reconhecimento de que o atual modelo de desenvolvimento existente é incapaz de resolver os problemas sociais e ambientais que ele acarreta. A atual crise social e ambiental existente não poderia ser identificada apenas e tão somente como resultado da ação predatória dos países do Norte, já que os sistemas econômicos adotados pelo Sul também são responsáveis tanto pela degradação ambiental quanto pelo fracasso em satisfazer as necessidades da maioria da população desses países. 


\section{CONSTRUÇÃO DO MODELO ANALÍTICO}

Os debates sobre as críticas do movimento ambientalista internacional aos projetos de MDL que estão sendo desenvolvidos em todo o mundo subdesenvolvido, com maior força na Ásia e na América Latina, conforme anteriormente mencionado, despertaram o interesse da primeira autora durante o desenvolvimento de sua dissertação de mestrado em administração, realizada na Escola de Administração da Universidade Federal da Bahia (UFBA). O objetivo daquele estudo era analisar as estratégias político-institucionais utilizadas por uma empresa brasileira, a Plantar S.A., para regular os conflitos socioambientais relativos a seu projeto de MDL.

Trata-se de um objeto ainda pouco estudado nas Ciências Sociais, desconhecendo-se, até o presente momento, outros estudos brasileiros avaliando a regulação de conflitos socioambientais ligados aos projetos de MDL. A análise das relações entre empresas proponentes e seus públicos de interesse (stakeholders), durante as etapas de elaboração, validação e aprovação, envolvidas no ciclo do projeto de MDL torna-se especialmente importante por conta de um dos requisitos básicos para a sua aprovação: a obrigatoriedade de a empresa proponente comprovar que ouviu a opinião dos atores sociais impactados pelo projeto, e ainda garantir que essa opinião foi levada em consideração no momento da formulação do mesmo.

Para a compreensão das similitudes e diferenças da ação contestatória realizada pelo movimento social ambientalista frente, utilizada por estes atores para externalizar os conflitos socioambientais existentes em relação aos projetos da Plantar, no Brasil, e da Botnia, no Uruguai, foi necessária a construção de um modelo de análise que englobasse as principais referências teórico-conceituais relativas à temática, definindo-se, em cada uma delas, as categorias analíticas e os indicadores a serem utilizados. O objetivo principal do modelo foi dotar o trabalho de um quadro teórico-conceitual estruturado para uma melhor análise dos objetos empíricos pesquisados. Esclarece-se, desde logo, que não se pretendeu, em nenhum momento, chegar a um esquema genérico e normativo, adaptável a toda e qualquer situação de ações contestatórias para a externalização de conflitos socioambientais.

Reconhece-se que o tema em questão possibilita diversos olhares. No entanto, o modelo de análise aqui proposto entende que a ação contestatória dos movimentos sociais ambientalistas representa a externalização de um conflito social e ambiental que é inerente a toda e qualquer questão ligada à utilização dos recursos ambientais. Desta forma, a observância da forma de ação dos principais atores sociais de contestação envolvidos em um conflito socioambiental para expressar sua opinião em relação a esta situação conflitiva, expondo, assim, as divergências de opinião existentes em relação à temática em questão, é fundamental para a compreensão não apenas do conflito propriamente dito, mas da abrangência e finalidade da ação contestatória realizada.

No presente estudo, esta análise tem como alvo-principal a compreensão das formas de contestação utilizadas por um dos principais atores políticos envolvidos na conflitiva questão dos projetos de MDL enquanto instrumentos de minimização das mudanças climáticas globais: os movimentos sociais ambientalistas. Esta análise deverá permitir um maior entendimento da lógica de ação deste ator social ao expressar sua opinião de protesto em relação às utilizações destes projetos para, supostamente, contribuir para a minimização das mudanças climáticas globais.

Com isto, propôs-se a utilização do seguinte esquema analítico:

Tabela 1: Modelo Analítico Adotado na Pesquisa

\begin{tabular}{|c|c|c|c|c|}
\hline Conceito & Componente & Sub-componente & $\begin{array}{l}\text { Categorias } \\
\text { Analíticas }\end{array}$ & Indicadores \\
\hline $\begin{array}{l}\text { Movimentos } \\
\text { Sociais } \\
\text { Ambientalistas }\end{array}$ & $\begin{array}{l}\text { Ação } \\
\text { Contestatória } \\
\text { contra }\end{array}$ & $\begin{array}{l}\text { Formas de } \\
\text { Externalização } \\
\text { dos Conflitos }\end{array}$ & $\begin{array}{l}\text { Situação- } \\
\text { Problema } \\
\text { Enfrentada }\end{array}$ & $\begin{array}{l}\text { - Metodologia } \\
\text { empregada no Projeto } \\
\text { de MDL }\end{array}$ \\
\hline
\end{tabular}




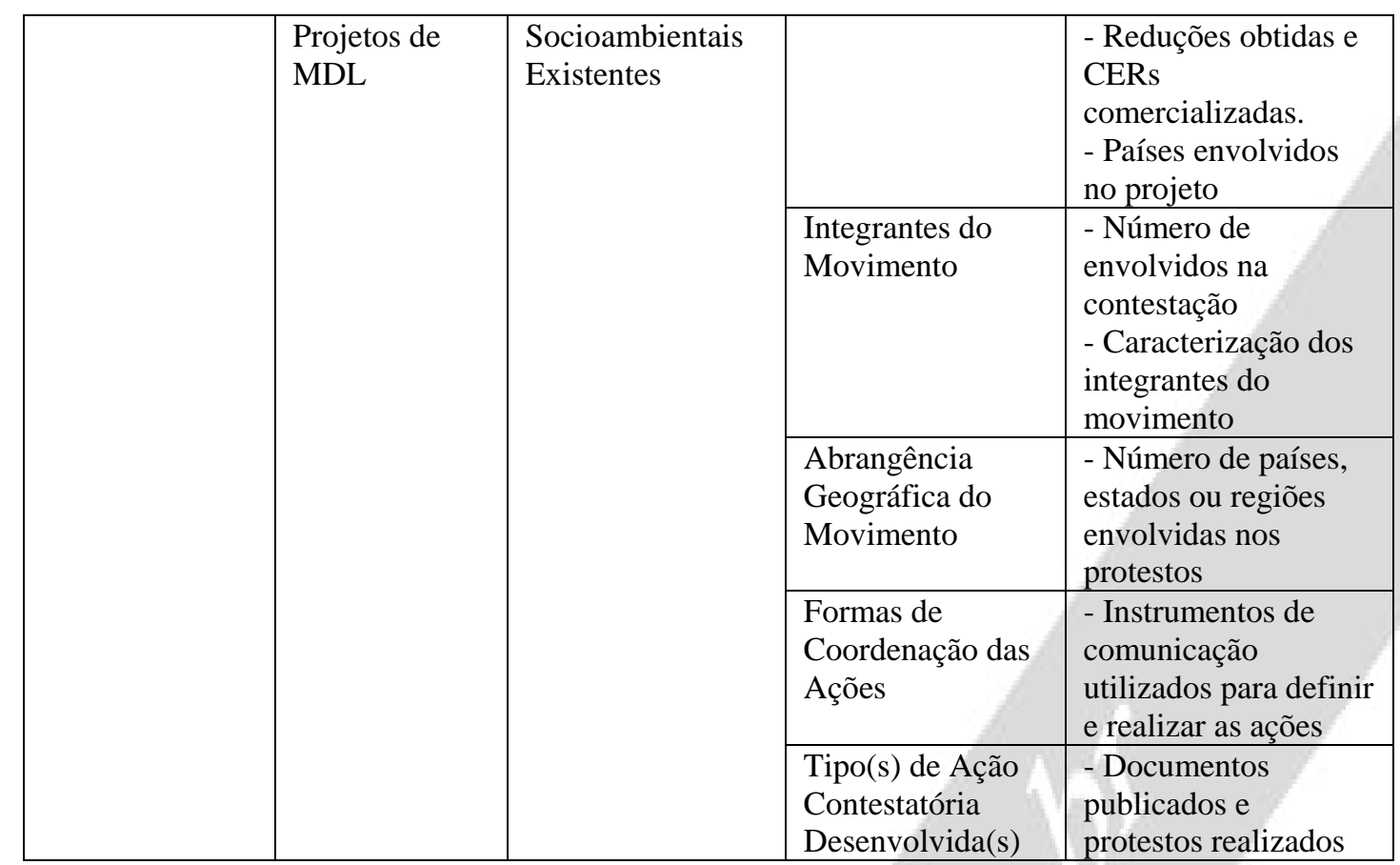

Fonte: Elaboração própria

Tendo como base este modelo analítico, foram analisados os Documentos de Concepção de Projeto (DCP) dos dois projetos aqui retratados, leituras analíticas de publicações realizadas em websites ambientalistas, realizadas entrevistas semi-estruturadas com diversos analistas da empresa Plantar, com integrantes do Movimento Contrário ao Projeto Plantar, com representantes das instituições que criticaram o projeto Fray Bentos, bem como com representante da DINAMA (Direccíon Nacional de Medio Ambiente), órgão integrante do Ministério de Vivienda, Ordenamiento Territorial y Médio Ambiente que, no Uruguai, é o responsável pela aprovação dos projetos. Apesar dos esforços empreendidos, não foi possível realizar-se entrevistas com representantes da empresa Botnia, proponente do projeto Fray Bentos, nem com representantes da Carbosur ou da Poyry, consultoras responsáveis pela elaboração do projeto. Procurou-se sanar tal limitação com a realização de análises aprofundadas em todos os textos disponibilizados no website da empresa em relação a sua atuação em Fray Bentos, incluindo-se, nestes materiais, descritivos da atuação socioambiental da empresa, estudos de impacto ambiental e social realizados, apresentações sobre o projeto de MDL implantado, bem como respostas da empresa aos questionamentos sobre este projeto.

\section{UMA FOTOGRAFIA DOS CONFLITOS EM ANÁLISE}

Diante da diversidade de aspectos envolvidos em cada um dos conflitos em análise, optou-se por uma tentativa de apresentação de fatos e dados, procurando dar ao leitor uma visão global dos dois casos para, posteriormente, realizar-se a análise sobre as principais implicações das semelhanças e disparidades encontradas entre os casos.

\subsection{O PROJETO PLANTAR: PIONEIRISMO E PARCERIA COM O BANCO MUNDIAL}

O Projeto Plantar foi desenvolvido pela Plantar Siderúrgica S.A, empresa brasileira localizada em Minas Gerais. A empresa é integrante do Grupo Plantar, que atua nos setores florestal e siderúrgico desde 1967. Trata-se da primeira parceria realizada pelo Banco Mundial, através de seu Fundo Protótipo de Carbono (PCF), para a execução de um projeto de MDL no mundo. Antes mesmo de ser analisado pela Comissão Interministerial de Mudança Global do Clima (CIMGC), órgão que no Brasil representa a Autoridade Nacional Designada (AND) para tratar de assuntos de MDL, o Projeto Plantar já havia comercializado parte de 
seus créditos de carbono com o PCF. Fundo Protótipo de Carbono (PCF), numa operação que envolve U\$ 5,3 milhões (Grupo Banco Mundial, 2002).

Em linhas gerais, o projeto pretende a redução de emissões de gases do efeito estufa por meio da utilização de combustível renovável (carvão vegetal proveniente de plantios de eucalipto) no lugar de combustível fóssil (coque de carvão mineral) ou biomassa nãorenovável (carvão vegetal de florestas nativas), na indústria de ferro gusa. O Projeto Plantar teria sido escolhido pelo PCF em virtude da grande possibilidade de replicação de sua metodologia em outros países do mundo (Grupo Banco Mundial, 2002).

Sua concepção completa é dividida em quatro atividades de projeto parcialmente integradas: a) a atividade florestal, através da remoção e estoque de gás carbônico (CO2) em 23.100 hectares de plantios de eucalipto, em áreas que estariam ocupadas por pastagem na ausência do projeto; b) a redução das emissões de metano (CH4) no processo de produção do carvão vegetal (carbonização da madeira), através de melhorias na eficiência do processo de produção; c) emissões de CO2 que foram evitadas através da utilização de carvão vegetal renovável (carbo-neutro) ao invés de coque ou biomassa não-renovável no processo de produção do ferro gusa; e d) realização de experimento de regeneração do cerrado abrangendo cerca de 400 hectares de vegetação nativa em terras não-florestadas, acima das exigências legais. Ressalta-se que esta última é uma atividade-piloto, não contabilizando RCEs (Grupo Plantar, 2008).

Durante seu processo de apreciação, ocorrido entre os anos de 2000 e 2001, as regulamentações do MDL referentes a sumidouros de carbono, denominadas LULUCF (Land Use, Land-Use Change and Forestry / Uso do Solo, Mudança de Solo e Florestas), ainda não estavam estabelecidas (o que só viria a ocorrer entre 2003 e 2004). Por esse motivo, a empresa teve que dividir seu projeto global em três projetos distintos: 1) mitigação de emissões de metano na produção de carvão vegetal; 2) reflorestamento como fonte renovável de suprimento de madeira para uso industrial; e, 3) mitigação de CO2 no processo de produção de ferro gusa, através do uso de carvão vegetal renovável (carbo-neutro) como fonte de energia termo-redutora (Ministério da Ciência e Tecnologia [MCT], 2007). Até o momento da finalização das pesquisas relativas aos conflitos socioambientais do Projeto Plantar, em maio de 2008, apenas a atividade de mitigação havia sido submetida e aprovada pela AND.

Não obstante as afirmações, por parte da Plantar, de que seu projeto de MDL traria diversos benefícios sociais e ambientais para a região onde seria desenvolvido - a exemplo de manutenção de floresta nativa preservada, preservação da fauna e da flora, proteção das nascentes d’água, implantação de corredores ecológicos, recuperação de áreas degradadas, criação de postos de trabalho nas áreas rurais, capacitação e educação ambiental aos trabalhadores (Prototype, 2007) -, diversos indivíduos e organizações direta ou indiretamente ligadas à atividade a ser desenvolvida iniciaram uma forte campanha por sua não aprovação. Ora em diante estas manifestações serão denominadas simplesmente "Movimento Contrário ao Projeto Plantar", ou apenas, "Movimento". De acordo com os dados levantados, a mobilização envolveu:

- Elaboração e envio de 5 (cinco) cartas-manifesto endereçadas aos investidores do Fundo Protótipo de Carbono (PCF) do Banco Mundial entre março e dezembro de 2003;

- Elaboração e envio de 1 (uma) carta-manifesto endereçada ao próprio Banco Mundial e à Presidência da República do Brasil, sendo copiada ao Ministério do Meio Ambiente, ao Governo do Estado de Minas Gerais e à Secretaria de Meio Ambiente do Estado de Minas Gerais, em dezembro de 2003;

- Reuniões e manifestações de organizações contrárias ao Projeto realizadas durante a realização do I $^{\circ}$ Fórum Social Brasileiro, ocorrido em 8 de novembro de 2003;

- Manifestações contrárias ao Projeto apresentadas durante a realização da Conferência 
sobre a Mudança Climática, realizada em Milão, Itália, em dezembro de 2003, culminando pela escolha do Projeto para receber o Prêmio Treetanic 2003, concedido ao "pior projeto de sumidouro de carbono do mundo";

- Elaboração e envio de 1 (uma) carta-manifesto endereçada ao Conselho Executivo de MDL, em junho de 2004;

- Elaboração, em 2004, de um vídeo-documentário denominado "Cartas em Vídeo", enviado aos investidores do PCF;

- Diversas publicações contrárias ao Projeto Plantar e à certificação FSC concedida às plantações da Plantar, publicadas nos boletins da WRM de números 65, 70, 74, 76 e 77, entre dezembro de 2002 e dezembro de 2003.

- Publicação das cartas-protesto elaboradas pelo Movimento no site da Sinkswatch, uma iniciativa do WRM para investigar os projetos de seqüestro de carbono envolvendo plantações florestais de eucalipto, destacando seus prejuízos às populações, aos ecossistemas e ao clima.

- Participação, em 2005, em espaço de discussões exclusivamente reservado ao Projeto Plantar, em Reunião de ONGs realizada no Canadá (Ventura, 2008).

O Movimento foi composto por representantes não apenas do estado de Minas Gerais, onde se localiza a Plantar, como também dos estados da Bahia, Espírito Santo e Rio de Janeiro. Entre seus 162 integrantes encontram-se: associações de geógrafos; pesquisadores da UFMG e da UFES; vereadores; deputados; organizações ambientalistas; organizações de defesa aos direitos humanos, aos direitos dos índios, de famílias carvoeiras e de trabalhadores de forma geral; associações de moradores; grupos de luta pelo campo e pela terra; e sindicatos de trabalhadores rurais. Constatou-se que um dos principais integrantes deste movimento foi a ONG de atuação internacional World Rainforest Movement (WRM, sigla em inglês para Movimento Mundial pelas Florestas), com sede no Uruguai.

Através da análise das cartas-manifesto acima citadas e das publicações no Boletim da WRM, verifica-se que o Movimento baseou sua argumentação em alguns pontos básicos, constantemente citados. O principal deles é que o Projeto Plantar não poderia ser aprovado pelo PCF enquanto um projeto de MDL, já que um de seus requisitos básicos, e razão de sua criação por parte da CQNUMC, não foi atingido: a contribuição para o desenvolvimento sustentável do país executante. Alega o Movimento que a produção de florestas de monocultura de eucalipto é totalmente incompatível com desenvolvimento sustentável (Ventura, 2008).

Essa alegação é feita com base em críticas existentes por parte de diversas organizações defensoras do meio ambiente, a exemplo da Rede Alerta contra o Deserto Verde e do WRM, ambos os atores extremamente atuantes no Movimento Contrário ao Projeto Plantar, bem como por pesquisadores do Brasil e do mundo. Para estes atores, a expansão da monocultura de eucalipto em larga escala causaria impactos negativos de caráter social, econômico, ambiental e cultural para as comunidades locais, a exemplo de: expulsão de comunidades tradicionais, aumento de desemprego, extinção da biodiversidade, danos à água e ao solo, causadas pelo uso de agrotóxicos, entre outros (Ventura \& Andrade, 2006).

Outro ponto de grande controvérsia apresentado pelo Movimento foi a questionabilidade da utilização da certificação FSC como um atestado de sustentabilidade para as monoculturas florestais. A própria certificação da Plantar, juntamente com a de outra empresa do setor florestal, teria sido objeto, em outubro de 2002, de uma avaliação coordenada pelo WRM, onde se concluiu pela necessidade de revisão nos critérios e princípios do FSC, no que tange a certificação de plantações florestais (World Rainforest Movement [WRM], 2007).

Especificamente em relação ao projeto de MDL da Plantar, o Movimento afirma, entre outras questões, que o seqüestro de carbono por plantações de árvores não seria capaz de 
garantir uma apreensão em longo prazo, já que, cedo ou tarde, o CO2 fixado será novamente liberado para a atmosfera, e que a substituição do carvão mineral pelo carvão vegetal não pode ser considerada menos prejudicial ao meio ambiente, no que tange à liberação de $\mathrm{CO} 2$, tendo em vista os problemas trazidos por uma plantação de eucalipto. Para o Movimento, apesar de a Plantar e o PCF alegarem que o Projeto trata, sobretudo, de 'substituição energética', entendem que trata de 'fixação de carbono' através de florestas de eucalipto, o que seria inaceitável enquanto projeto de promoção de desenvolvimento sustentável (Ventura, 2008).

Houve, ainda, inúmeras críticas relativas à empresa Plantar propriamente dita, no que diz respeito a sua gestão socioambiental (relacionamento com partes interessadas, aspectos trabalhistas, impactos ao meio ambiente, uso desordenado do solo, desrespeito ao modo de vida das populações tradicionais, entre outras).

Com base no modelo de análise acima exposto, observou-se que, no que tange aos Conflitos Socioambientais, a categoria analítica dos interesses de cada ator estratégico envolvido pôde ser identificada nos argumentos da Plantar, que considera seu projeto um benefício ao desenvolvimento sustentável do Brasil, por trazer contribuições sociais e ambientais à região onde está localizada, bem como nas razões expostas pelos integrantes do movimento, argumentando, entre outros aspectos, que as plantações de eucalipto utilizadas são incompatíveis com a sustentabilidade do planeta como um todo e, principalmente, da região onde a empresa está instalada.

No que se refere ao conceito-chave de Movimentos Sociais de Contestação, também ressaltado no modelo analítico adotado, verifica-se a composição múltipla deste movimento, formado por indivíduos e organizações de diferentes estados brasileiros, e até mesmo do exterior, pertencentes a diversos setores produtivos. Seu foco de atuação deu-se de diversas maneiras, utilizando-se desde comunicação escrita dirigida aos tomadores de decisão do Protocolo de Kyoto, mas circulada por toda a internet em listas de grupos ambientalistas, como também de manifestações em encontros estratégicos e elaboração de vídeos expondo a situação problema em debate.

Desta forma, o movimento conseguiu que o objeto de sua contestação fosse conhecido por um grande número de pessoas, obtendo, ao final, ganhos significativos junto à empresa proponente que, conforme exposto em Ventura (2008), alterou sua forma de relacionamento com as comunidades do entorno de sua fábrica, promoveu melhorias significativas em sua gestão ambiental, e procurou articular-se até mesmo com a certificadora FSC, visando a incrementarem, conjuntamente, os requisitos de sustentabilidade de plantações florestais de eucalipto, e ao governo brasileiro, buscando a um posicionamento nacional mais coeso em relação a projetos de MDL.

\subsection{PROJETO FRAY BENTOS DE BIOMASSA: CRÍTICAS PONTUAIS EM MEIO A CONFLITO TRANSFRONTEIRIÇO}

Até o momento, o Uruguai só teve três projetos analisados e aprovados pela UNFCCC como passíveis de serem enquadrados como projetos de MDL, no âmbito do Protocolo de Kyoto. Um deles foi submetido pela empresa finlandesa Oy Metsa Botnia, conhecida simplesmente por Botnia, segunda maior produtora de pasta de celulose da Europa (WRM, 2006). A empresa detém quatro subsidiárias, sendo duas delas localizadas no Uruguai: a Compañia Forestal Oriental S.A. (FOSA), responsável pela plantação de eucaliptos, estabelecida em 1990, e a Botnia S.A, produtora de pasta de celulose que iniciou seu processo de instalação no país em 2003.

A Botnia S.A. localiza-se na cidade de Fray Bentos, a 1,1 km do acesso à ponte internacional Libertador General José de San Martin, uma das ligações entre Uruguai e Argentina. Antes mesmo de propor seu projeto de MDL à AND uruguaia, em dezembro de 
2006, a empresa já vinha sendo alvo de inúmeras críticas por parte do movimento ambientalista, e especial pelo movimento "No a las papeleras. Si a la vida.", capitaneado pela Asamblea Ciudadana Ambiental de Gualeguaychú (ACAG), localizada na cidade argentina vizinha de Fray Bentos, com que faz divisa através do Rio Uruguai (Pakkasvirta, 2008).

O projeto de MDL proposto consiste da geração de um excedente de $32 \mathrm{MW}$ de eletricidade, a partir de biomassa encontrada no "licor negro", um resíduo da produção de pasta de celulose que tem a madeira de eucalipto como matéria-prima. Trata-se, assim, de um projeto de substituição de geração elétrica a partir de combustíveis fósseis (carvão queimado nas caldeiras) por biomassa renovável. Propõe-se que a eletricidade gerada na planta de cogeração industrial não utilizada pela própria Botnia seja vendida à rede pública de eletricidade. De acordo com o DCP, haveria um ganho ao desenvolvimento sustentável do Uruguai, tendo em vista estar-se gerando eletricidade a partir do licor negro "que es una fuente limpia y renovable de energia (...) con claras ventajas para la mitigación del calentamiento global” (Poyry \& Carbosur, 2006, pág. 3).

A empresa afirma que, através deste projeto de MDL, é possível gerar energia elétrica excedente às plantas de celulose convencionais, tendo em vista modificações e melhorias nos processos tecnológicos. Soma-se a isso o fato de que a empresa teria sido desenhada para consumir menor quantidade de energia, contribuindo para a geração de energia excedente, estando, assim, "claramente alineado com los postulados del MDL de promoción Del desarrollo sostenible y transferência de tecnologia a los países en desarrollo” (Poyry \& Carbosur, 2006, pág. 6). De acordo com seu DCP, além dos impactos ambientais (redução de uso de carvão fóssil, e, consequentemente, de emissão de GEE), o projeto traria impactos sócio-econômicos positivos, tendo em vista a contribuição para a segurança energética do Uruguai.

Obviamente, o projeto Fray Bentos, antes de ser submetido à UNFCCC, teve que passar pela análise e aprovação da AND uruguaia, papel exercido pelo MVOTMA. É importante ressaltar que o governo uruguaio vem buscando uma política participativa no que se refere à sua gestão ambiental, tanto que, para a aprovação de projetos de MDL, antes do posicionamento final governamental, ocorre uma submissão a um grupo (Comisión Técnica Asesora de la Proteción Del Médio Ambiente) integrado por representantes do governo, de empresas, de universidades, e de ONGs (Swiss Federal Institute of Technology [ETH] \& Ministerio de Vivienda, Ordenamiento Territorial y Medio Ambiente [MVOTMA], 2003).

Foi justamente neste momento, durante o processo de coleta de opiniões sobre o projeto Fray Bentos, que se realizaram as críticas à sua aprovação. Não obstante a concretização deste projeto não ter sido totalmente pacífica, não se pode afirmar a formação de um movimento social contrário a ele. Isto porque, durante a fase de avaliação do projeto, realizada pela DINAMA com o auxílio da comissão multissetorial de análise da contribuição dos projetos de MDL ao desenvolvimento sustentável do Uruguai, houve a elaboração e disseminação de dois documentos bastante críticos solicitando a sua não aprovação. São eles:

- Parecer conjunto da Red Uruguaya de ONGs Ambientalistas (RED) e da Asociacion Nacional de ONGs (ANONG) denominado "Comentários sobre a Avaliação da Contribuição ao Desenvolvimento Sustentável do Projeto: Geração de Energia Elétrica a partir da Biomassa em Fray Bentos”, encaminhado à DINAMA em novembro de 2006.

- Carta-manifesto da WRM publicada no boletim de número 109 da organização, de agosto de 2006. Esta mesma carta foi enviada ao Conselho Executivo de MDL no mesmo ano, e circulada entre participantes da COP 12, realizada em Nairóbi, na África, também no ano de 2006.

Em seus comentários ao projeto Fray Bentos, a RED e a ANONG afirmam que um dos principais problemas do projeto em análise é a impossibilidade de se separar o projeto de 
MDL do empreendimento da Botnia como um todo. Para as organizações, não são claros os limites que separam o projeto da planta de celulose (Asociacion Nacional de ONGs [ANONG] \& Red Uruguaya de ONGs Ambientalistas [RED], 2006). Para elas, até mesmo o documento de análise do FBBP elaborado pela DINAMA carrega consigo, em diversos trechos, uma indissocibilidade entre projeto de MDL e projeto da planta de celulose.

Isto ocorre especialmente porque o projeto Fray Bentos utiliza resíduos do processo de produção de pasta de celulose. Estes resíduos serão gerados, independentemente da geração ou não de energia elétrica. Para este ator não-estatal da Governança Ambiental, os impactos sociais e ambientais da produção de celulose são grandes e, se depende dos resíduos desta produção para se ter o licor negro que será queimado e transformado em energia elétrica, não se pode falar em desenvolvimento sustentável.

Aliado a esta crítica, encontra-se o posicionamento da WRM, segundo ator a realizar questionamentos sobre o projeto de MDL da Botnia, trabalhando, para isso, em parceria com o Grupo Guayubira. Para eles, é efetivamente impossível dissociar-se este projeto de todo o processo produtivo da Botnia. Desta forma, além dos impactos da produção de pasta de celulose, deve-se levar em consideração os problemas sociais, econômicos e ambientais relativos à produção da matéria-prima utilizada pela empresa, ou seja, a monocultura de eucalipto. Nestas mesmas críticas, está incluído o fato de que a empresa estaria obtendo lucros duplos em uma mesma atividade de "geração de excedente de energia": a venda de eletricidade e de créditos de carbono (WRM, 2006).

Os impactos a que os atores sociais se referem foram amplamente discutidos durante a fase de construção da planta de celulose da Botnia, especialmente durante os anos de 2005 e 2006. Os conflitos socioambientais relativos a esta construção, que estava ocorrendo concomitantemente com a de outra empresa de celulose, a espanhola Ence, culminaram com o fechamento, por parte do movimento ambientalista contrário às "papeleiras", de uma ponte internacional que liga Uruguai e Argentina. Estes conflitos geraram sérios abalos na relação diplomática entre os dois países, sendo que, até o presente momento, não houve uma decisão definitiva por parte da Corte de Haya, responsável pela solução de problemas relativos ao uso do Rio Uruguai (Palermo \& Reboratti, 2007).

A aplicação do modelo de análise proposto para o estudo das contestações ao Projeto de MDL da Botnia, assim como ocorreu no Projeto Plantar, permitiram verificar as ações contestatórias realizadas por integrantes do movimento ambientalista, como forma de externalização dos conflitos socioambientais existentes em relação aos projetos de Mecanismo de Desenvolvimento Limpo (MDL). Verificou-se que a contestação ao Projeto Botnia foi bastante pontual, sendo que a composição do "movimento" restringiu-se a, basicamente, três organizações uruguaias.

Obviamente, não se pode desconsiderar o fato de que as três organizações (Red Uruguaia de ONGs Ambientalistas, Asociación Nacional de ONGs e WRM) são formadas por diversos indivíduos e ONGs. No entanto, os documentos elaborados como forma de expressar sua contestação não receberam a assinatura destes integrantes, conforme afirmado pelos próprios entrevistados, integrantes destas organizações, o desconhecimento destes outros membros em relação ao objeto desta contestação.

Esta afirmação é corroborada pela dificuldade encontrada, por parte desta pesquisadora, em encontrar integrantes da Red e/ou da Anong que pudessem participar da pesquisa. Todos os integrantes contatados indicavam tão somente um membro da organização que poderia responder às questões, pesquisador integrante do Centro Uruguayo de Tecnologias Apropriadas (CEUTA), o que de fato ocorreu.

O foco de atuação do "movimento", ou mais precisamente sua forma de expressão, que se restringiu à elaboração de dois documentos de crítica (um enviado à própria DINAMA, e outro enviado ao Conselho Executivo de MDL e, posteriormente, distribuído entre 
participantes da COP 12, em Nairóbi, no ano de 2006, culminando por ser publicado em um website ambientalista), pode ser considerado um dos principais limitadores à que a contestação obtivesse um maior número de apoiadores. A isso, se soma a opinião expressa em entrevista por ambos os integrantes desta contestação: o assunto "negociação de créditos de carbono” é ainda muito incipiente no Uruguai, sendo de difícil entendimento pela maior parte das pessoas. Desta forma, é difícil encontrar adeptos que venham a unir-se às manifestações contrárias a projetos de MDL no país (WRM, 2008b; RED, 2008).

\section{Comparativo entre as Contestações a Projetos de MDL no Brasil e no Uruguai}

Tendo-se em vista que o objetivo principal do presente estudo é realizar uma análise comparativa entre as ações contestatórias do movimento ambientalista contrário a projetos de MDL, tomando-se como casos ilustrativos os projetos da Plantar e da Botnia, procurou-se analisar os dados obtidos, acima apresentados, tendo como lente analítica o quadro teóricometodológico apresentado no item 2 deste trabalho.

Desta forma, obtiveram-se os seguintes resultados: 
Tabela 2: Análise Comparativa entre os Dois Projetos de MDL Estudados

\begin{tabular}{|c|c|c|c|}
\hline $\begin{array}{l}\text { Categorias } \\
\text { Analíticas }\end{array}$ & Indicadores & Projeto Plantar & Projeto Fray Bentos \\
\hline $\begin{array}{l}\text { Situação- } \\
\text { Problema } \\
\text { Enfrentada }\end{array}$ & $\begin{array}{l}\text { - Metodologia } \\
\text { empregada no Projeto } \\
\text { de MDL } \\
\text { - Reduções obtidas e } \\
\text { CERs } \\
\text { comercializadas. } \\
\\
\text { - Países envolvidos } \\
\text { no projeto }\end{array}$ & $\begin{array}{l}\text { - Três metodologias } \\
\text { distintas, sendo a mais } \\
\text { contestada o uso das } \\
\text { plantações florestais de } \\
\text { eucalipto como sumidouros } \\
\text { de carbono. } \\
\text { - Média de } 46.428 \\
\text { toneladas de carbono } \\
\text { equivalente/ano. Parte das } \\
\text { CERs compradas pelo } \\
\text { PCF, do Banco Mundial. } \\
\text { - Brasil e Nova Zelândia }\end{array}$ & $\begin{array}{l}\text { - Queima de licor negro } \\
\text { (subproduto industrial } \\
\text { da planta de celulose } \\
\text { que tem o eucalipto } \\
\text { como matéria prima) } \\
\text { como biomassa } \\
\text { renovável. } \\
\text { - Média de } 39.636 \\
\text { toneladas de carbono } \\
\text { equivalente/ano. CERs } \\
\text { ainda não } \\
\text { comercializadas. } \\
\text { - Uruguai (e Finlândia, } \\
\text { indiretamente). }\end{array}$ \\
\hline $\begin{array}{l}\text { Integrantes do } \\
\text { Movimento }\end{array}$ & $\begin{array}{l}\text { - Número de } \\
\text { envolvidos na } \\
\text { contestação } \\
\\
\text { - Caracterização dos } \\
\text { integrantes do } \\
\text { movimento }\end{array}$ & $\begin{array}{l}\text { - Mais de } 160 \text { assinantes } \\
\text { das cartas-manifesto. } \\
\text { - Indivíduos e organizações } \\
\text { (ambientalistas, sociais, } \\
\text { universidades, entre outras) } \\
\text { de vários países do mundo. }\end{array}$ & $\begin{array}{l}\text { - Apenas } 3 \\
\text { organizações assinantes } \\
\text { das publicações. } \\
\text { - Duas organizações } \\
\text { ambientalistas de } \\
\text { atuação nacional e uma } \\
\text { internacional. }\end{array}$ \\
\hline $\begin{array}{l}\text { Abrangência } \\
\text { Geográfica do } \\
\text { Movimento }\end{array}$ & $\begin{array}{l}\text { - Número de países, } \\
\text { estados ou regiões } \\
\text { envolvidas nos } \\
\text { protestos }\end{array}$ & $\begin{array}{l}\text { - Representantes de três } \\
\text { países, integrantes de } \\
\text { quatro diferentes estados da } \\
\text { federação. }\end{array}$ & $\begin{array}{l}\text { - Representantes do } \\
\text { Uruguai. }\end{array}$ \\
\hline $\begin{array}{l}\text { Formas de } \\
\text { Coordenação das } \\
\text { Ações }\end{array}$ & $\begin{array}{l}\text { - Instrumentos de } \\
\text { articulação utilizados } \\
\text { para definir e realizar } \\
\text { as ações }\end{array}$ & $\begin{array}{l}\text { - Circulação de listas de } \\
\text { apoio ao movimento na } \\
\text { internet, troca de e-mails e } \\
\text { telefonemas, encontros } \\
\text { presenciais em eventos. }\end{array}$ & $\begin{array}{l}\text { - Aparentemente, os } \\
\text { atores contrários ao } \\
\text { projeto de MDL não se } \\
\text { articularam para definir } \\
\text { ações conjuntas. }\end{array}$ \\
\hline $\begin{array}{l}\text { Tipo(s) de Ação } \\
\text { Contestatória } \\
\text { Desenvolvida(s) }\end{array}$ & $\begin{array}{l}\text { - Documentos } \\
\text { publicados e } \\
\text { protestos realizados }\end{array}$ & $\begin{array}{l}\text { - Cartas-manifesto } \\
\text { apresentadas a tomadores } \\
\text { de decisão e circuladas pela } \\
\text { internet, boletins da WRM, } \\
\text { artigos em sites } \\
\text { ambientalistas, vídeo } \\
\text { documentário, } \\
\text { participações e protestos } \\
\text { em eventos internacionais. }\end{array}$ & $\begin{array}{l}\text { - Relatório da RED- } \\
\text { ANONG contrário ao } \\
\text { projeto e entregue à } \\
\text { AND uruguaia, boletim } \\
\text { da WRM circulado na } \\
\text { internet e distribuído } \\
\text { em evento } \\
\text { internacional. }\end{array}$ \\
\hline
\end{tabular}

Fonte: Elaboração própria, 2009.

No que tange à situação problema originadora dos conflitos socioambientais que seriam alvo das ações contestatórias, é fundamental atentar-se para o fato de que, em ambas, o projeto de MDL responsável pelos conflitos externalizados envolvem tem como empresa proponente uma indústria ligada às grandes corporações de plantio de eucalipto. Este tipo de plantação, normalmente realizada sob a forma de monocultivos, é altamente criticado por pesquisadores e organizações ambientalistas em todo o mundo (Andrade, 2000; Koopmans, 1999; Ventura, 2008). 
Quando se traz a questão dos monocultivos de eucalipto para figurar como alternativa de redução de GEE, o conflito tende a se agravar (Ventura 2008; WRM, 2008). A utilização destas plantações como parte das estratégias de "sumidouros de carbono" traz uma questão muito específica: ao mesmo tempo em as árvores que removem o CO2 da atmosfera, liberam certa quantidade do mesmo gás, e emitem, ainda, óxido nitroso e metano. No entanto, apesar de haver emissão de gases, a Decisão 17/CP.7 do Acordo de Marraqueche autoriza considerar essas atividades como de remoção, sendo, portanto, passíveis de integrar o Protocolo. Trata-se do tipo de projeto que ainda provoca maiores incertezas dentre os elencados pelo Protocolo de Kyoto. De acordo com Lopes (2002), no âmbito do MDL, as definições e modalidades dessas atividades devem considerar questões de não-permanência, adicionalidade, fuga, incertezas e impactos socioeconômicos e ambientais.

A atividade de reflorestamento, relacionada aos "sumidouros", foi o principal objeto de críticas ao Projeto Plantar. Batizado de "Reflorestamento como Fonte Renovável de Suprimento de Madeira para Uso Industrial no Brasil”, o projeto só foi submetido em novembro de 2008, sendo validado pela Entidade Operacional Designada em março de 2009 (MCT, 2009). Ao tempo da submissão desta atividade à AND brasileira, a empresa já havia passado por um impactante aprendizado organizacional sobre o relacionamento políticoinstitucional a ser adotado com as partes interessadas, o que se acredita tenha sido um dos principais responsáveis pela ausência de novas e contundentes críticas por parte do movimento ambientalista.

Mais especificamente em relação aos projetos de MDL (e não à ação contestatória propriamente dita), percebe-se que a principal semelhança que une os dois casos analisados é o pioneirismo de cada um deles em seus respectivos países. Assim como o Projeto Plantar foi um dos primeiros a comercializar seus créditos no Brasil, visto ter obtido a parceria do PCF do Banco Mundial antes mesmo do início da vigência do Protocolo de Kyoto (Grupo Plantar, 2008), o mesmo ocorre com o projeto Fray Bentos, terceiro projeto uruguaio aprovado pela UNFCCC (UNFCCC, 2009).

Nas ações contestatórias aos dois projetos analisados, percebem-se fortes críticas ao MDL enquanto instrumento de minimização às mudanças climáticas globais, que apenas manteria o modelo de desenvolvimento (capitalista, neoliberalista, de exploração dos países do Norte sobre os do Sul, entre outros aspectos). No entanto, no caso do Projeto Plantar, percebe-se uma orientação muito mais clara neste sentido, visto que todas as contestações realizadas trazem elementos claramente relacionados com as críticas do movimento antialterglobalista.

Já no caso do projeto Fray Bentos, não obstante a RED-ANONG ter se oposto a aceitar os argumentos de que a Botnia contribuiria para o desenvolvimento sustentável do Uruguai, é na ação da WRM que se verifica fortes críticas ao padrão de desenvolvimento perpetuado através do projeto em questão.

O número de CERs a ser comercializada em cada um dos projetos estudados não foi alvo de críticas por parte do movimento ambientalista. Em realidade, as ações contestatórias realizadas procuraram ressaltar, mais do que tudo, seu inconformismo em relação à comercialização de créditos de carbono, ou seja, sua luta contra o comércio de carbono como forma de minimização das mudanças climáticas. Especificamente em relação aos projetos analisados, nos dois casos o movimento ambientalista expressou seu entendimento de que, não deveria haver nenhum tipo de ganho das empresas com as atividades de projeto propostas tendo em vista que, em ambos os projetos, não se verificava um dos requisitos básicos para a aprovação de projetos de Mecanismo de Desenvolvimento Limpo. Não se verificava a contribuição do mesmo para o desenvolvimento sustentável.

A categoria analítica dos integrantes do movimento permite a verificação de uma semelhança - a presença da ONG World Rainforest Movement (WRM) que, além de ser uma 
organização conhecida em todo o mundo por suas críticas ao modelo de plantio de árvores de crescimento rápido, revelou-se uma das organizações ambientalistas mais atuantes a integrar o movimento contrário a projetos de MDL no mundo -, e muitas diferenças.

Verifica-se que o número de integrantes que se uniu para protestar contra o Projeto Plantar (movimento com mais de 160 integrantes) é expressivamente maior do que no Fray Bentos (com apenas três organizações participantes, não chegando a conformar-se em um movimento específico). Além disto, na contestação ao Projeto Plantar, verificou-se a presença de organizações e indivíduos de diversos setores sociais (ONGs, associações, entidades filantrópicas, professores universitários, entre outros), enquanto que nas críticas ao projeto Fray Bentos de MDL somente percebeu-se a presença de ONGs ambientalistas.

No que tange à abrangência geográfica das ações contestatórias ocorridas, percebe-se marcantes diferenças entre os projetos analisados. Entre os manifestantes contrários ao Projeto Plantar, encontrou-se pessoas e organizações de países diversos. Mesmo os representantes brasileiros desta contestação eram oriundos de quatro diferentes estados do país. Na contestação ao Fray Bentos, apenas organizações uruguaias sediadas em Montevidéu fizeram-se representar.

Os dados encontrados revelam grandes diferenças, também, no que diz respeito às formas de coordenação das ações de contestação realizadas. De acordo com as informações colhidas junto às duas organizações contrárias à aprovação do projeto Fray Bentos, parece não ter houve havido articulação entre estes atores para a realização de ações de contestação coordenadas. Para os fins desta análise, Red e Anong não podem ser consideradas como duas organizações que se uniram para realizar um protesto, tendo em vista que a primeira é parte integrante da segunda. Neste caso, o importante é a constatação de que RED - ANONG não se articulou com a WRM para verificar a melhor forma de atuar para expressar os conflitos relativos ao projeto de MDL da Botnia.

Em contrapartida, na contestação ao Projeto Plantar, houve forte mobilização dos indivíduos e organizações participantes dos protestos, que circularam pela internet as cartasmanifesto a serem apresentadas, coletaram assinaturas virtualmente, organizaram encontros, entre outros.

Finalmente, o tipo de ação contestatória desenvolvida em ambos os projetos revela, mais uma vez, pontos de semelhança e divergências, sendo estas últimas as mais visíveis. Como ponto em comum pode ser citado o fato de que, tanto os manifestantes contrários ao Projeto Plantar como ao Fray Bentos utilizaram documentos escritos (cartas-manifesto) circuladas na internet (em sites ambientalistas e listas de discussão), ou não, para externalizar os pontos de conflito existentes. Também nos dois casos foi possível observar-se a participação em COPs. No entanto, na ação do movimento da Plantar, esta ação foi muito mais ativa, realizando-se verdadeiros protestos, e não apenas a distribuição de um manifesto.

Mais uma vez, observa-se, na análise do tipo de contestação, a força da manifestação contra o Projeto Plantar muito mais forte do que no Fray Bentos. Em relação ao Plantar, foi utilizado um número muito maior de documentos escritos, publicados, e, principalmente, foram realizados protestos durante eventos importantes para a tomada de decisões da governança ambiental global. Além disto, foi elaborado um vídeo documentário que continua circulando o mundo pela internet.

\section{CONSIDERAÇÕES FINAIS}

A presente pesquisa teve como objetivo a verificação das principais semelhanças e diferenças existentes nas ações contestatórias dos movimentos sociais ambientalistas na América Latina, para externalizar a existência de conflitos socioambientais relativos a projetos de Mecanismo de Desenvolvimento Limpo (MDL). Em nenhum momento pretendeu-se esgotar a análise sobre as principais semelhanças que unem projetos de MDL na 
América Latina, nem ao menos diferenças que podem separá-los. O objetivo foi o de apresentar os resultados encontrados em dois casos específicos, em que projetos de MDL receberam críticas por parte de atores sociais da governança ambiental.

Conforme verificado no decorrer desta pesquisa, no novo contexto mundial configurado pela globalização, novos atores sociais passam a conquistar cada vez mais espaço nas decisões da governança mundial. Além dos Estados, atores como as organizações internacionais, as ONGs, as grandes corporações internacionais, e os movimentos sociais transnacionais estão sendo forçados a dialogar sobre problemáticas que ultrapassam completamente as fronteiras do nacional, a exemplo das mudanças climáticas globais.

Considerando-se a criticidade dos problemas ambientais atualmente enfrentados, verifica-se um crescimento do reconhecimento da importância e necessidade de se discutir alternativas de desenvolvimento para a humanidade. Isto, necessariamente, engloba indivíduos e organizações de todo o mundo, tanto do Norte quanto do Sul, que possuem relações diferenciadas com as formas de uso e apropriação dos recursos naturais, acarretando, com isso, conflitos socioambientais de ordem múltipla, em diversos níveis.

Sabendo-se que o MDL é o único mecanismo do Protocolo de Kyoto que, até o momento, permite a participação de países em desenvolvimento e, havendo-se um consenso de que estes países também devem dar a sua contribuição para a minimização dos GEE na atmosfera terrestre para, assim, diminuir as mudanças climáticas globais, entende-se que a compreensão das ações contestatórias contra estes projetos (seus argumentos, formas de ação, principais integrantes, entre outros aspectos) é fundamental para compreender possíveis alterações a serem realizadas em âmbito nacional e até mesmo regional, pelos países hospedeiros, em caso de permanência destes projetos no Pós-Kyoto (instrumento que está sendo elaborado pela Governança Ambiental Global, e que deverá substituir o Protocolo de Kyoto após 2012).

A análise aqui realizada recaiu sobre um projeto brasileiro, o Projeto Plantar, que teve críticas alçadas ao âmbito mundial (especialmente por se tratar do primeiro projeto de "sumidouros de carbono" a ser comercializado no mercado de carbono e, também, conta da parceria da empresa brasileira com PCF do Banco Mundial), e um projeto uruguaio, o Projeto Fray Bentos, cujas manifestações ficaram, em sua maioria, circunscritas ao âmbito nacional (possivelmente ofuscadas pelo conflito internacional que envolveu a empresa finlandesa Botnia, em sua subsidiária uruguaia, com seus vizinhos argentinos, somado ao fato do pouco conhecimento da população local a respeito dos créditos de carbono). Não obstante esta marcante diferença em termos de abrangência de manifestações e críticas, o fato de ambos envolverem a temática da utilização de plantações de eucalipto como possíveis atenuantes da mudança climática global é um fator muito importante a ser considerado, especialmente quando se discute a inclusão deste tipo de estratégia nas Reduções de Emissão do Desmatamento e da Degradação (REDD), uma possível inclusão do Pós-Kyoto.

Entretanto, a pesquisa demonstrou que existem diferenças significativas entre a forma de contestação deste movimento em relação a cada projeto. Conforme visto no capítulo anterior, a contestação realizada contra a Plantar foi muito mais vigorosa e abrangente do que a realizada contra a Botnia, tanto em número de atores envolvidos, abrangência geográfica dos protestos, e até mesmo em relação às formas de contestação utilizadas. Diante da forma de coordenação das ações de contestação ao Projeto Plantar e da situação-problema (conflito socioambiental) por ele enfrentado, a contestação é mais facilmente reconhecida em suas características de movimento de contestação transnacional.

Em realidade, apesar de haverem mais diferenças do que semelhanças entre as ações contestatórias realizadas contra os dois projetos analisados, não é possível desprezar-se ou minimizar-se as similitudes encontradas. Percebeu-se que o movimento ambientalista critica fortemente o modelo de desenvolvimento que seria perpetuado por instrumentos como o 
MDL. A utilização da internet como instrumento de comunicação e difusão de informações, idéias e ideais também pode ser entendida como um forte ponto em comum entre ambas as contestações analisadas. Efetivamente, as novas tecnologias de comunicação vêm reduzindo as fronteiras entre os países.

A maior diferença entre as ações esteve centrada na abrangência do movimento, tanto em termos numéricos como em termos geográficos. De acordo com os atores uruguaios entrevistados, isto se deveu, principalmente, à falta de politização ambiental da sociedade uruguaia que não havia se envolvido intensamente, sequer, com os protestos relativos à instalação da Botnia naquele país. Para eles, não é possível esperar que, em um país onde, atualmente, não há oposição, visto que o atual governo assumiu as mesmas estratégias de desenvolvimento (insustentável, de acordo com os atores) das gestões anteriores, tenha consciência política e ambiental suficiente para engajar-se em um protesto que envolve questões altamente complexas e de caráter global.

Obviamente, a pesquisa realizada apresenta limitações, a exemplo da não realização de entrevistas com a proponente do projeto uruguaio e a pouca observação não participante realizada no Uruguai. Buscou-se reduzir tais limitações com uma profunda análise documental. Faz-se necessário, assim, obter-se informações complementares a presente pesquisa, com a realização de entrevistas com a empresa Botnia e com outros críticos de projetos de MDL em todo o mundo, visando a uma maior robustez dos dados aqui apresentados, buscando-se conhecer, com maior profundidade, o movimento ambientalista contrário aos projetos de MDL e suas lógicas de ação.

Recomenda-se, ainda, a realização de novos estudos sobre críticas a projetos de MDL outros países em desenvolvimento, buscando identificar os principais aspectos que podem estar impedindo sua contribuição para a minimização das mudanças climáticas globais e também ao desenvolvimento sustentável dos países hospedeiros. Acredita-se que, desta forma, poder-se-á, com a participação de outros atores da governança ambiental global, além dos Estados, construir instrumentos que possam, efetivamente, trazer benefícios para o Planeta como um todo, e para as populações que nele habitam.

Espera-se que, com o aprofundamento dos estudos sobre os conflitos socioambientais relativos a projetos de MDL e sobre as formas de contestação a ele realizadas, possa-se contribuir para a reflexão e o fortalecimento da governança ambiental global e, desta forma, com a busca de soluções e alternativas para a sustentabilidade da humanidade e de todo o Planeta.

\section{REFERÊNCIAS}

Alvarado, R. (2007). Política forestal, plantas de celulosa y debate ambiental. Uruguay trás um nuevo modelo de desarrollo. In: Palermo, V. e Reboratti, C. De outro lado del rio. Buenos Aires: Edhasa.

Asociacion Nacional de Ongs (ANONG) e Red Uruguaya de Ongs Ambientalistas (RED). (2003). Propuesta de Criterios de Desarrollo Sostenible para la Aprobación de Proyectos en el Marco del Mecanismo para un Desarrollo Limpio.

Comissão Interministerial Sobre Mudança Global do Clima (CIMGC). (2003). Resolução n. 1. Brasília, setembro de 2003.

Echart, E., López, S. e Orozco, K. (2005). Origen, Protestas y Propuestas Del Movimiento Antiglobalización. Catarata e Instituto Universitario de Desarrollo y Cooperación (IUDC). Madrid. 
ETH (Swiss Federal Institute of Technology) e Mvotma (Ministerio De Vivienda, Ordenamiento Territorial Y Medio Ambiente). (2003). Host Country Approval of CDM Projects in Uruguay: application of a sustainability assessment tool.

Grupo Banco Mundial. (2002). Project Appraisal Document for the PCF Minas Gerais Plantar Project. Abril, 2002. Enviado por e-mail a Ventura, A. C. (andreaventura@oi.com.br)

Grupo Plantar. (2008). Projeto Carbono. Disponível em <http://www.plantar.com.br/>. Acesso em: 05 jan. 2008

Instituto Brasileiro de Análises Sociais e Econômicas (IBASE). (1995). Conflitos sociais e meio ambiente: desafios políticos e conceituais. Rio de Janeiro.

International Emission Trading Association (IETA). (2006). Brazil opens carbon credit market. Disponível em

$<$ http://www.ieta.org/ieta/www/pages/index.php?IdSitePage=954 >. Acesso em: 24 nov. 2006.

Koopmans, J. (1999). Além do eucalipto: o papel do Extremo Sul. Salvador: Memorial das Letras.

Lopes, I. V. (Coord.). (2002). O Mecanismo de Desenvolvimento Limpo - MDL: Guia De Orientação. Rio de Janeiro: Fundação Getúlio Vargas.

Milani, C. R. S.; Keraghel, C. (2007). The International Agenda for Sustainable Development: International Contestatory Movements. In: Thoyer, S.; Martimort, B. (Org.). Participation for Sustainability in Trade. 1 ed. Londres: Ashgate Publishers, v. 1, p. 93-109.

Ministério da Ciência e Tecnologia (MCT). (2007). Mitigação de Emissões de Metano na Produção de Carvão Vegetal da Plantar. In: Projetos Aprovados nos Termos da Resolução $n^{o}$ 1. Disponível em <http://www.mct.gov.br/index.php/content/view/47722.html >. Acesso em: 01 jun. 2007.

Pakkasvirta, J. (2008). From Pulp to Fiction? Fray Bentos Pulp Investment Conflict through the Finnish Media. Cooperation \& Conflict, Sage (London) No. 4/2008.

Palermo, V. e Reboratti, C. (2007). Del Otro Lado Del Río: ambientalismo y política entre uruguayos y argentinos. Buenos Aires: Edhasa.

Poyry e Carbosur. (2006). Botnia: Generation de Electricidad a Partir de Biomassa. Proyecto bajo El Mecanismo de Desarrollo Limpio de Metsa-Botnia en Fray Bentos. Julho de 2006. Disponível em http://www.uruguayinforme.com/news/21072006/21072006_botnia_biomasa.php. Acesso em 25 set. 2008

Red Uruguaia de Ongs Ambientalistas. (2008). Entrevista concedida por integrante sobre as críticas ao Projeto Fray Bentos. [Out. 2008]. Entrevistadora: Andréa C. Ventura. 
SouthSouthNorth. (2004). Climate Change and the Kyoto Protocol's Clean Development Mechanism. London: ITDG Publishing.

Torres, C.A.R., Costa e Silva, F.E., e Cunha, I.A. (2005). Resolução de conflitos ambientais e gerenciamento ambiental. Anais do VIII Encontro Nacional de Gestão Empresarial e Meio Ambiente (ENGEMA). Rio de Janeiro/RJ, FEA (USP), EAESP (FGV-SP) e EBAPE (FGV$\mathrm{RJ})$.

United Nations Framework Convention on Climate Changes (UNFCCC). (2009). Clean Development Mechanisms (CDM) Statistics. Disponível em: http://cdm.unfccc.int/Statistics/index.html. Acesso em 09 de julho de 2009.

Ventura, A. C. e Andrade, J. C. (2006). O Protocolo de Kyoto e a Inauguração de um Novo Mercado Financeiro para o Brasil. Anais do Congresso Acadêmico de Meio Ambiente (CADMA). Niterói, RJ.

Ventura, A. C. (2008). Mecanismo de Desenvolvimento Limpo (MDL): uma análise da regulação de conflitos socioambientais do Projeto Plantar. Dissertação de Mestrado. Escola de Administração/UFBA.

Viola, E. (2005). As Complexas Negociações Internacionais para Atenuar as Mudanças Climáticas. In: Meio Ambiente no Século XXI. Trigueiro, A. (Coord.), Armazém do Ipê Autores Associados, $4^{\mathrm{a}}$ ed., Campinas/SP.

World Rainforest Movement (WRM). (2006). Brazil: Eucalipto e Conferencia sobre a Mudança climática em Milão. Disponível em <http://www.wrm.org.uy/alerts/december03.html>. Acesso em 20 dez. 2006

- (2007). Evaluation report of V\&M Florestal Ltda. and Plantar S.A. Reflorestamentos, both certified by FSC - Forest Stewardship Council. Brasil, novembro de 2002. Disponível em <http://www.wrm.org.uy/countries/Brazil/fsc.html>. Acesso em: 01 ago. 2007

. (2008). The Botnia pulp mill project intends to profit from climate change. Publicado no Boletim WRM n. 109, de agosto de 2006. Disponível em http://www.wrm.org.uy/bulletin/109/Uruguay.html. Acesso em 16 out 2008.

(2008). Entrevista concedida por integrantes da WRM, sobre as críticas ao Projeto Fray Bentos. [Out. 2008]. Entrevistadora: Andréa C. Ventura. 